\title{
PERILAKU SOSIAL MUSLIM TERHADAP LGBT DALAM FILM CINTA FIISABIILILLAH VERSI YOUTUBE
}

\section{MUSLIM SOCIAL BEHAVIOR TOWARDS LGBT IN THE FILM CINTA FIISABIILILLAH ON YOUTUBE}

\author{
Rifa Ulfayati Huri ${ }^{\mathbf{1}^{*}}$, Sukarelawati ${ }^{2}$, Maria Fitriah ${ }^{3}$ \\ ${ }^{123}$ Ps Sains Komunikasi Fakultas Ilmu Sosial dan Ilmu Politik, Universitas Djuanda Bogor, \\ Jl. Tol Ciawi No 1 Kotak Pos 35 Bogor 16770. \\ *Korespondensi: Rifa Ulfayati Huri, rifaulfayatihuri@gmail.com
}

(Diterima oleh Dewan Redaksi: 01-02-2019)

(Dipublikasikan oleh Dewan Redaksi: 01-04-2019)

\begin{abstract}
This study aims to find out Muslim social behavior towards LGBT in the film Cinta Fiisabiilillah on Youtube. This study used a qualitative approach and descriptive analysis research method by carrying out data collection techniques using primary data and secondary data. Primary data is in the form of observations and interviews. While secondary data is in the form of documentation. The object of research is the Cinta Fiisabiilillah Film. The results showed that Muslim social behavior towards LGBT in the film Cinta Fiisabiilillah was to accept and embrace it to hijrah Fiisabiilillah together and not move away because of its poor past.
\end{abstract}

Keywords: Behavior, LGBT, Film

\begin{abstract}
ABSTRAK
Penelitian ini bertujuan untuk mengetahui perilaku sosial muslim terhadap LGBT dalam Film Cinta Fiisabiilillah di Youtube. Penelitian ini menggunakan pendekatan Kualitatif dan metode penelitian deskriptif analisis dengan melakukan teknik pengambilan data menggunakan data primer dan data sekunder. Data primer berupa hasil observasi lapangan dan wawancara. Sedangkan data sekunder berupa hasil dokumentasi. Objek penelitian penelitian adalah Film Cinta Fiisabiilillah. Hasil penelitian menunjukkan bahwa perilaku sosial muslim terhadap LGBT dalam film Cinta Fiisabiilillah adalah menerima dan merangkulnya untuk hijrah Fiisabiilillah bersama serta tidak menjauhinya karena masa lalunya yang kurang baik.
\end{abstract}

Kata Kunci: Perilaku Sosial, LGBT, Film

Rifa Ulfayati Huri, 2019. Perilaku Sosial Muslim Terhadap LGBT dalam film Cinta Fiisabiilillah versi Youtube. 


\section{PENDAHULUAN}

Berdasarkan kajian KEMENPPA (2015), LGBT di Indonesia masih menjadi hal yang tabu khususnya bagi kelompok yang pemikirannya didasari agama. Sebagian besar menghujat perilaku dan orientasi seksual kelompok LGBT. Hal tersebut terungkap dalam temuan Saiful Mujani Research and Consulting (SMRC) melalui sejumlah survey nasional, yang hasilnya disampaikan kepada pers oleh peneliti senior SMRC Ade Armanto bahwa Survey nasional (Surnas) SMRC menunjukkan 57,7 $\%$ publik berpendapat bahwa LGBT punya hak hidup di negara kita. Ada pun yang menyatakan tidak menyetujui hanya sebesar $41,1 \%$. Secara umum, keberadaan film disuatu negara mencerminkan kondisi sosial dan budaya bangsa tersebut (BBC Indonesia, 2018).

Berdasarkan fenomena tersebut sebuah Production House memproduksi film dengan mengangkat cerita tentang Cinta, Persahabatan dan perbedaan serta sikap lainnya yang menimbulkan beberapa perilaku sosial sebagai seorang muslim saat menghadapi permasalahan terkait Gay dalam film tersebut. Terdapat beberapa adegan yang memperlihatkan perilaku social terhadap kasus Gay yang dapat dipandang dari pandangan masyarakat secara umum sehingga film tersebut menarik untuk di teliti secara kualitatif dengan judul "Perilaku Sosial Muslim terhadap LGBT dalam Film Cinta Fii Sabiilillah Versi Youtube". Hingga 4 Juli 2018 Cinta Fiisabiilillah telah ditonton Sebanyak 208.498 kali.

Menurut Max Weber (2001) dalam Nisrima (2016), tindakan sosial ada empat tipe yaitu 1) Tindakan rasionalitas instrumental (berorientasikan tujuan) 2) Tindakan rasional nilai (berdasarkan nilai) 3) Tindakan afektif (Tindakan yang dipengaruhi emosi 4) Tindakan tradisional (Tindakan karena kebiasaan)

Berdasarkan penjelasan diatas maka dirumuskan masalah yaitu Bagaimana perilaku sosial Muslim terhadap LGBT dalam Film Cinta Fii Sabilillah di Youtube. Adapun tujuan dari penelitian ini adalah untuk mengetahui perilaku sosial Muslim terhadap LGBT dalam Film Cinta Fii Sabilillah di Youtube.

\section{MATERI DAN METODE}

Penelitian ini menggunakan pendekatan deskriptif kualitatif. Menurut Moleong (2007), penelitian kualitatif adalah penelitian dimaksudkan untuk memahami fenomena terkait sesuatu yang dialami subjek penelitian, misalnya persepsi, perilaku, motivasi, tindakan, dan lain-lain dengan cara deskriptif pada suatu konteks khusus yang alamiah dalam bentuk kata-kata dengan memanfaatkan berbagai metode alamiah. Idrus (2009) secara sederhana mengatakan bahwa penelitian kualitatif adalah meneliti informan sebagai subjek penelitian dalam lingkungan hidup kesehariannya. Menurut Hasan (2002) data Primer ialah data yang dikumpulkan atau diperoleh langsung dari lapangan oleh orang yang melakukan penelitian serta pemahaman orang bersangkutan yang memerlukannya. Data primer diperoleh dari sumber informan baik individu atau kelompok seperti hasil wawancara yang dilakukan peneliti.

Observasi yang dilakukan yaitu melakukan pengamatan terhadap ide dan alur cerita yang dimiliki Film Cinta Fii Sabiilillah serta karakter pemain dan kesesuaiannya dengan objek penelitian. Sedangkan wawancara dilakukan kepada 7 narasumber yaitu M. Ali Ghifari sebagai Penulis Naskah film Cinta Fiisabiilillah, Gus Arif selaku Tokoh Agama dan pembina pesantren. 5 informan pendukung yang menjadi narasumbernya diambil dari penonton yaitu Fatwatul Aini sebagai Mahasiswa, Izzah Julaeha sebagai mahasiswa, Nova Sapriadi sebagai pegawai swasta, Titut Andriani sebagai Pembantu Rumah Tangga, Nurul Suci Fatimah sebagai pegawai swasta

Data sekunder, menurut Sugiyono (2010), adalah sumber data yang tidak 
memberikan data secara langsung kepada pengumpul data, melainkan lewat pihak lain atau lewat dokumen. Data sekunder yang digunakan pada penelitian ini melalui hasil grafik, gambar dan dokumentasi.

\section{HASIL DAN PEMBAHASAN}

Cinta Fiisabiilillah adalah sebuah film yang bercerita tentang 6 orang muslim yaitu Hafidz yang sombong, perempuan bercadar, cowok tampan, tajir, dan taqwa tapi gay, perempuan smart yang jatuh cinta lelaki gay, selebgram yang ber make up untuk menutupi kekurangan wajahnya, dan muallaf yang jatuh cinta pada selebgram. Tujuan diproduksinya film Cinta Fiisabiilillah dengan alur dan plot cerita yang complicated ini adalah untuk menyatukan perbedaan dibanding persamaan. Selaku Penulis naskah Ali Ghifari mengatakan bahwa Film ini dibuat dengan konten LGBT juga didasarkan pada pandangan dari FMM yang menganggap bahwa LGBT itu adalah orang yang hanya diberi ujian lebih dari orang biasa serta bertujuan untuk menyatukan perbedaan dibanding persamaan.

Berdasarkan hasil wawancara film Cinta Fiisabilillah menampilkan sebuah adegan, FA (23) menyebutkan LGBT yang ia dapatkan dari film tersebut adalah menyukai sesama jenis dari adegan saat Herman memutuskan pasangannya dan pasangan Herman menolak. Hal tersebut turut diungkapkan oleh TA (29) bahwa informasi LGBT tersebut terletak pada sebuah kenyataan dimana Herman sebagai pemeran Gay dalam film tersebut berusaha menjauh dari dunia kelamnya sebagai seorang Gay dan menyadari bahwa ia dengan pasangannya tidak dapat bersatu sebagai pasangan kekasih.

Sedangkan bentuk LGBT dari sebuah karakter, disebutkan oleh NS (23) bahwa semua konten LGBT yang terdapat dalam film Cinta Fiisabiilillah termasuk ke dalam perbuatan haram dan yang lebih menarik perhatian NS adalah saat ada adegan seorang perempuan yang meminta untuk dinikahi oleh Herman yang merupakan seorang Gay dan akan menerima aibnya sebagai seorang Gay.

Selanjutnya berdasarkan pesan moral FA (23) mengungkapkan bahwa pesan moral yang didapat adalah tidak pernah melihat orang lain dengan masa lalunya. Tetapi lihat orang dengan kebaikannya serta niatnya untuk merubah diri. Hal serupa diungkapkan oleh TA (29) bahwa setiap manusia itu memiliki masa lalu yang kurang baik dan tidak langsung menghakimi seseorang saat mengetahui aibnya. Tetapi harus menerima dan merangkulnya untuk bisa melangkah bersama dalam hijrah Fiisabiilillah karena tidak luputnya manusia dari salah. Sementara bagi IJ (21), ia menjadi tahu bagaimana cara untuk menunjukkan cinta kepada seseorang dengan seharusnya dan seperti yang Islam ajarkan.

Dalam perilaku sosial muslim terhadap LGBT dalam film Cinta Fiisabililah di Youtube, tokoh agama dan akademisi GA (38) mengatakan bahwa sebagai seorang muslim harus coba memberikan pemahaman memakai cara yang baik dan memberikan pemahaman bahwasannya manusia diciptakan untuk berpasangpasangan seperti yang disebutkan dalam Q.S. An-Nisa.

Central route dalam perilaku sosial terhadap LGBT berdasarkan wawancara IJ (21) berpendapat bahwa ia tidak menyetujui hal tersebut, namun tidak memungkiri bahwa faktanya hal itu ada dan dekat dengan kita. IJ mengungkapkan sebagai muslim wajib untuk mengingatkan dan mengajak mereka kepada kebaikan dan kembali ke jalan yang benar. TA (29) mengungkapkan bahwa perlu pengetahuan dalam menyikapi hal ini, meskipun LGBT memang tidak untuk muslim

Sedangkan peripheral route di mana penerima pesan tidak memikirkan informasi yang didapat dipikirkan secara kritis dan tidak mempertimbangkan isi pesan tersebut. NS (23) mengatakan bahwa sikap yang diambil saat menghadapi LGBT adalah dengan mengikhlaskan dan 
meridhoi keburukannya serta tetap menjadikannya sebagai kawan meski memiliki rasa suka terhadap kita seta utuk tidak menjauh dan tetap menjaga hubungan baik dengan mereka, kita pun memberi tahu bahwa hal tersebut adalah kurang baik. Hal senada disebutkan FA (23) bahwa ia sedikit merasa dinilai kurang etis setelah menonton film tersebut karena terdapat konten LGBT. Namun FA jadi berpikir saat ini siapa pun yang menjadi LGBT dia sedang khilaf dan dipastikan suatu saat akan berubah jika mereka memiliki niat untuk berubah dan sikap serta pandangannya terhadap LGBT tidak terlalu negatif setelah menonton Cinta Fiisabiilillah.

\section{KESIMPULAN DAN IMPLIKASI}

\section{Kesimpulan}

Adanya beberapa bentuk LGBT dalam Cinta Fiisabiilillah berdasarkan adegan terletak pada sebuah kenyataan di mana Herman sebagai Gay dalam film tersebut berusaha menjauh dari dunia kelamnya sebagai seorang Gay. Karakter yang dimainkan dengan menunjukkan usaha Herman untuk bertaubat sebagai seorang Gay dengan meninggalkan perbuatannya dengan pasangan gaynya. Pesan moral yang disampaikan yaitu masyarakat dapat menghargai perbedaan dan menilai seseorang dengan tidak melihat masa lalu kurang baik yang pernah dimilikinya tetapi usaha bertaubat dan niat baiknya.

Perilaku yang dilakukan seseorang terutama muslim terhadap LGBT adalah tidak menjauh dan tetap menjaga hubungan yang baik dan memberi tahu serta memberikan pemahaman dengan cara yang baik bahwa LGBT adalah hal yang kurang baik.

\section{Implikasi}

Implikasi dalam penelitian ini adalah dapat memanfaatkan media Youtube dalam membentuk perilaku sosial masyarakat.

\section{DAFTAR PUSTAKA}

Hasan, Iqbal. 2002. Metodologi Penelitian dan Aplikasinya. Jakarta. Ghalia Indonesia

Idrus, Muhammad. 2009. Metode Penelitian Ilmu Sosial, Pendekatan Kualitatif dan Kuantitatif. Jakarta : Erlangga

KEMENPPA. 2015. Laporan Kajian "Pandangan masyarakat terhadap Lesbian, gay, biseksual dan transgender (LGBT) di Jakarta, Bogor, Depok dan Tangerang". Pusat Penelitian Kesehatan Universitas Indonesia.

Moleong, Lexy J. 2007. Metodologi Penelitian Kualitatif. Penerbit PT Remaja Rosdakarya Offset, Bandung

Nisrima, Siti. 2016. Pembinaan Perilaku Sosial Remaja Penghuni Yayasan Islam Media Kasih Kota Banda Aceh". Volume 1, Nomor 1: 192-204. Pendidikan Kewarganegaraan. Universitas Syiah Kuala.

Sugiyono. 2010. Metode Penelitian Pendidikan Pendekatan Kuantitatif, Kualitatif, dan $R$ \& D. Bandung: Alfabeta

https://www.bbc.com/indonesia/indonesia$\underline{42813753}$ 